\title{
Spatial distribution and temporal changes in the fish populations of Lake Victoria
}

\author{
Albert Getabu ${ }^{a}$, Rhoda Tumwebaze ${ }^{\mathrm{b}}$, David N. MacLennan ${ }^{\mathrm{c}, *}$ \\ ${ }^{a}$ Kenya Marine and Fisheries Research Institute, P.O. Box 1881, Kisumu, Kenya \\ ${ }^{b}$ Department of Fisheries Resources, P.O. Box 4, Entebbe, Uganda \\ ${ }^{c}$ The Orchard, Muirhall Road, Perth PH2 7BQ, Scotland, UK
}

Accepted 17 December 2002

\begin{abstract}
The fisheries of Lake Victoria in East Africa must be managed effectively to ensure sustainable food supplies. This has been impossible in the past due to inadequate knowledge of commercially important fish stocks. Here we present the first acoustic abundance estimates of fish in Lake Victoria. Five lakewide acoustic surveys were conducted between 1999 and 2001, using the Simrad EY500 echo-integrator with a 120 $\mathrm{kHz}$ split-beam transducer. There are many species of fish in Lake Victoria, however, only limited identification of targets can be achieved by present methods. Broad categories were distinguished by visual examination of echo-traces. The echo-integrals were partitioned between four target groups: (1) the Nile perch (Lates niloticus), a top predator, (2) small pelagics comprising mainly the dagaa Rastrineobola argentea together with mixed species of haplochromines, (3) the crustacean Caridina nilotica and (4) other species. Spatial and temporal differences in the Standing Crop were observed between north and south, and between shallow and deep water. Most fish were found inshore but the spatial distribution varied between seasons. Mid-lake fish densities were higher in August compared to February. In August, the water column is well mixed while in February it is stratified with a low-oxygen layer inhospitable to fish near the bottom. There are consequent changes in the characteristics of observed echo-traces. Over the survey series, Nile perch biomass showed a consistent decline, while the stocks of small pelagic species increased. We emphasize the need for simple rules to identify species, and hydrographic monitoring to assist echo-trace classification. In the absence of any other source of comprehensive biomass estimates, the value of acoustic surveying in Lake Victoria is demonstrated.
\end{abstract}

(C) 2003 Éditions scientifiques et médicales Elsevier SAS and Ifremer/IRD/Inra/Cemagref. All rights reserved.

Keywords: Acoustic survey; Fish stock estimation; Species identification; Lake Victoria

\section{Introduction}

Lake Victoria is the second largest lake in the world by surface area, covering $68000 \mathrm{~km}^{2}$ in East Africa. It has a mean depth of $40 \mathrm{~m}$ and a shoreline of $3450 \mathrm{~km}$, which is shared by the bordering states of Kenya, Tanzania and Uganda. The lake is an important source of food, employment and earnings for the riparian communities through the exploitation of fish resources.

The fisheries of Lake Victoria have undergone drastic changes in its recent history. The introduction of the Nile perch Lates niloticus has had major ecological consequences (Goudswaard et al., 2002). It is thought that some 200 endemic species of haplochromines (which previously com-

* Corresponding author.

E-mail address: maclennan22@aol.com (D.N. MacLennan). prised about $90 \%$ of the fish biomass) have become extinct from the lake due to predation by the Nile perch (Witte et al., 2000). In the 1960s, the fisheries sustained a production of around 100000 ton per year, although even then there were signs of overexploitation (Reynolds and Greboval, 1988). The fisheries now produce over 500000 ton of fish annually. The considerable increase after 1979 came from the developing Nile perch population. The present fisheries are much simpler than before, being dominated by only three species: the Nile perch, the Nile tilapia (Oreochromis niloticus) and the dagaa (Rastrineobola argentea). In recent years, however, as fishing pressure on the Nile perch intensified, there have been signs of recovery in at least some of the prey species (Witte et al., 2000).

Research on the lake fisheries is essential to support management initiatives intended to ensure sustainable food sup- 


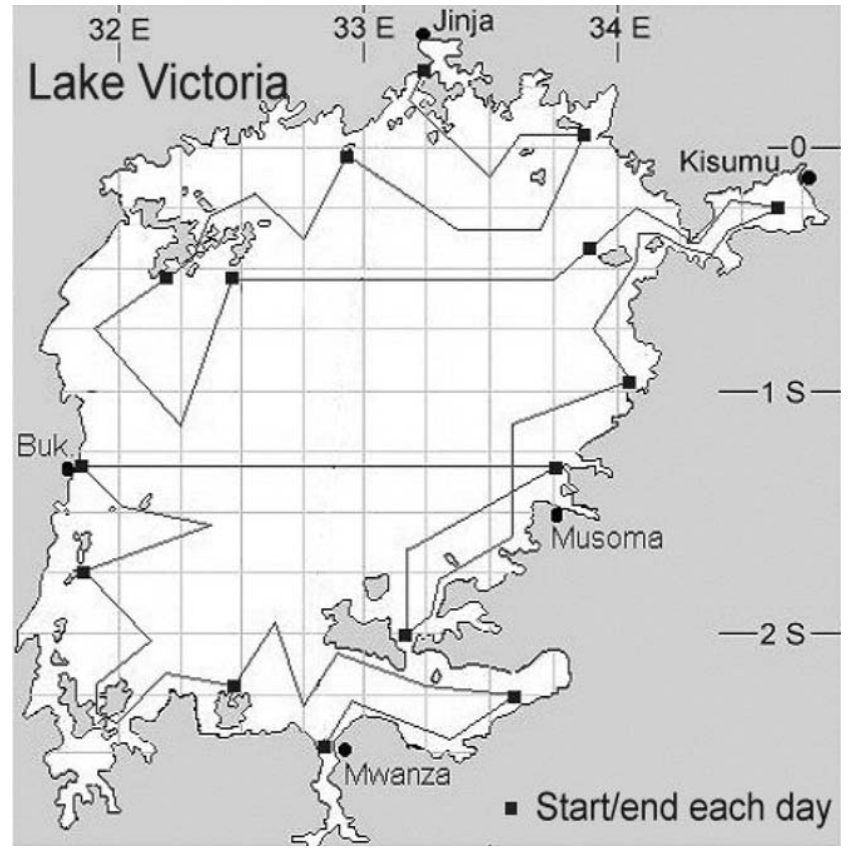

Fig. 1. Stratified track design with most effort applied inshore, as used in August 1999. Fourteen-day survey from Mwanza to Jinja.

plies in the region. In recognition of this need, Phase II of the Lake Victoria Fisheries Research Project (LVFRP) was implemented from 1997 until the end of 2001. Acoustic surveying was a central component of the LVFRP programme. Five surveys were conducted at 6-month intervals starting in August 1999. Each survey covered the whole of Lake Victoria. In this paper, we describe the methods used and some of the results obtained from these surveys.

\section{Materials and methods}

The surveys were done using the research vessel "Victoria Explorer" which is a $16.5 \mathrm{~m}$ long stern trawler. A $120 \mathrm{kHz}$ split-beam transducer with $9^{\circ}$ beam width between $3 \mathrm{~dB}$ down points was mounted on the vessel's hull. The transducer was connected to a Simrad EY500 echo-integrator controlled by a Toshiba Satellite laptop computer. The echointegrator was calibrated twice during each survey using the standard target method (MacLennan and Simmonds, 1992). The reference target was initially a $23 \mathrm{~mm}$ copper sphere (TS $=-40.4 \mathrm{~dB}$ ) and, for the fifth survey only, a $33.2 \mathrm{~mm}$ tungsten carbide sphere $(\mathrm{TS}=-40.6 \mathrm{~dB})$.

\subsection{Survey design}

The surveys were designed as a series of transects crossing the lake, normally starting from Mwanza, Tanzania and ending in Jinja, Uganda Figs. 1, 2. Practical constraints limited the extent to which a completely even transect design could be achieved. There are many islands scattered throughout Lake Victoria. The surveys were conducted primarily during the daylight hours, with the vessel going to anchor or lying at

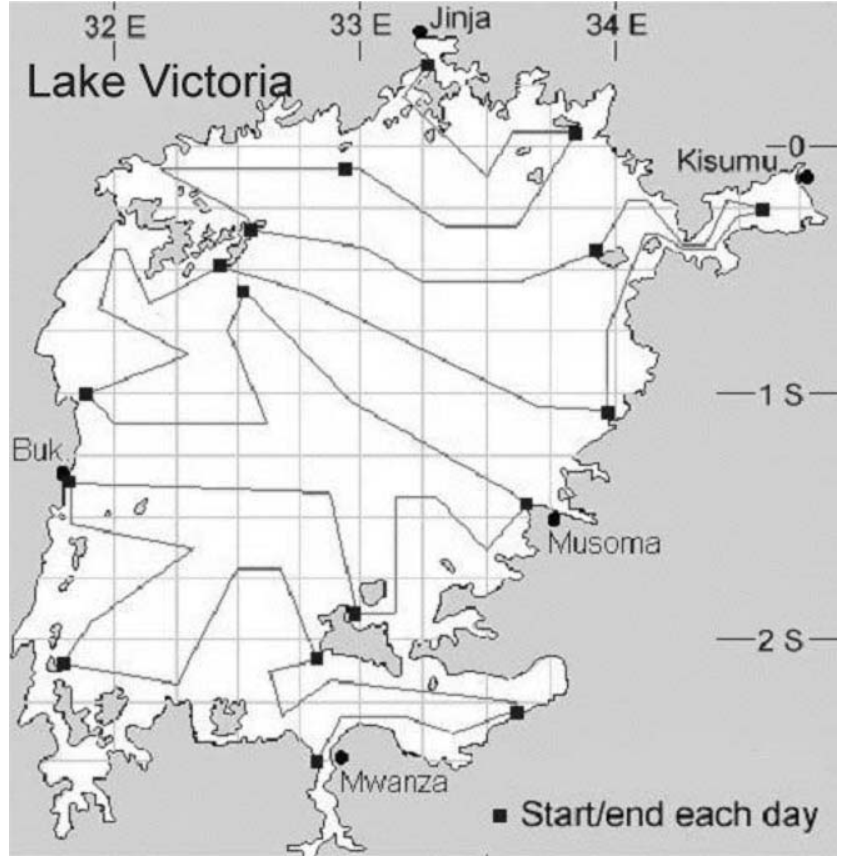

Fig. 2. Uniform design giving a more even coverage of the whole lake, as used in February 2000 onwards. Sixteen-day survey from Mwanza to Jinja.

a jetty overnight. The transect design had to allow the vessel to reach a suitably sheltered location at the end of each day. The surveying speed of "Victoria Explorer" is about 10 knots. The cross-lake transects are up to 140 miles long, thus some $30 \%$ of the longest transect had to be covered in darkness. The behaviour of fish is well known to depend on the light level, and after dark there were concentrations of plankton in the water not seen in the daytime. We were unable to fully allow for these day-night differences. It was, therefore, important to minimise the amount of survey track covered at night. The logistical constraints, however, did not allow a daytime-only survey. The first survey, in August 1999, was designed as a stratified sampling scheme, which provided more intensive surveying of the shallow inshore areas Fig. 1]. The results showed that more sampling was needed in the offshore mid-lake areas. Extra survey time was, therefore, allocated to allow additional cross-lake transects. Fig. 2 shows the resulting design, which was more uniform than before. The new transect scheme was followed with minimal modification on the second and later surveys.

\subsection{Echo-trace sampling}

During the first four surveys, a $3.5 \times 3.5 \mathrm{~m}$ frame trawl with $26 \mathrm{~mm}$ mesh and a $5 \mathrm{~mm}$ liner in the codend was used to sample the echo-traces in midwater. The frame trawl was effective in sampling small haplochromines and the dagaa, $R$. argentea. It caught very few of the larger Nile perch which can easily escape from such a small net. A bottom trawl with $22.6 \mathrm{~m}$ headrope, codend mesh $25 \mathrm{~mm}$ and a vertical opening of $3.5 \mathrm{~m}$ was used alternately with the frame trawl to sample the largest fish, which were mostly found close to the lakebed. A pelagic trawl (codend mesh size $26 \mathrm{~mm}$ and $5 \mathrm{~mm}$ 
liner) was obtained for "Victoria Explorer" in May 2001. During the last survey, this gear was used instead of the frame and bottom trawls. The mouth opening of the pelagic trawl is about $10 \times 10 \mathrm{~m}$. The pelagic trawl proved to be much more effective at catching the larger Nile perch. Fish up to $96 \mathrm{~cm}$ in length were caught. After each trawl haul, the catch was sampled to determine the species and size composition.

\subsection{Data recording}

The echo-integration was performed in a series of consecutive layers covering the whole water column from $5 \mathrm{~m}$ below the transducer (changed to $3 \mathrm{~m}$ in the 2001 surveys) to $0.5 \mathrm{~m}$ above the bottom. The layers were $5 \mathrm{~m}$ thick down to $20 \mathrm{~m}$ depth and $10 \mathrm{~m}$ thick in deeper water. Echograms and tables showing the nautical area scattering coefficient (NASC) for each layer were printed at 6 min intervals. This corresponds to about 1 nautical mile $(1852 \mathrm{~km})$ of cruise track. Position data (from a Garmin GPS Navigator) and the NASC values for each 6 min interval were entered on an Excel spreadsheet for subsequent analysis of biomass and distribution. Additionally, the echo data (ping interval $0.5 \mathrm{~s}$ ) were stored on the Toshiba hard disk in real time, and later downloaded to recordable compact disks for permanent archiving.

\subsection{Partitioning the echo-integrals}

The NASC is a single measure of all the detected targets. This needs to be partitioned among such target categories as can be separately identified, i.e. individual species or species groups. There was a limit to what could be achieved in this respect. A complete breakdown to species level was not practicable. Some knowledge of aquatic ecology and the behaviour of fish as regards aggregation and vertical movement was necessary to decide what level of partitioning was reasonable.

In our surveys, the partitioning was done in two stages. Firstly, the total NASC was divided among "selections". This was based on general knowledge revealed by the trawl catches, the appearance of characteristic echo-traces and their depth. We adopted five selections, called Sel 1 through 5 , which are defined as follows.

- Sel 1: Near-surface dagaa schools; strong, individual marks down to $15 \mathrm{~m}$ depth.

- Sel 2: Mixed pelagic layer; mostly dagaa and haplochromines, some Nile perch.

- Sel 3: Mixed bottom layer; mostly haplochromines and Nile perch, some dagaa.

- Sel 4: Diffuse deep layer; mostly composed of Caridina nilotica with some Barbus profundus.

- Sel 5: Mixture of fish and plankton; diffuse traces everywhere, only seen at night.

Fig. 3 shows an example where Sel 1, Sel 2 and Sel 3 appear in the same echogram. The selections are distinguished by the appearance and/or the depth of the echotraces.

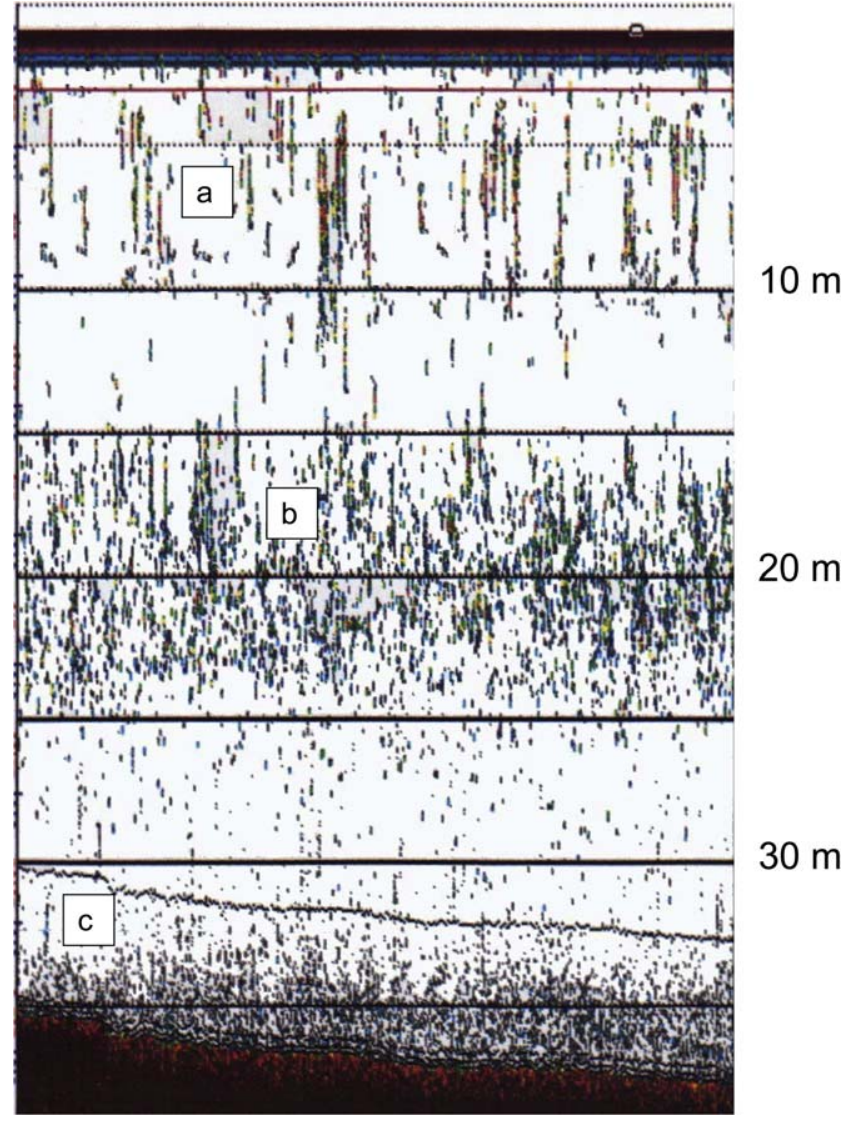

Fig. 3. Example of three of the selections used for echo-trace partitioning. (a) The strong narrow marks above $15 \mathrm{~m}$ are dagaa schools; (b) the patchy marks $15-20 \mathrm{~m}$ are the pelagic mixture - Nile perch, dagaa and Haplochromines; (c) the diffuse weak echoes near the bottom are mainly Caridina shrimp.

The first stage of partitioning was done for each integration interval, by allocating the NASC for each 5 or $10 \mathrm{~m}$ depth interval to one selection. Only measurements above $15 \mathrm{~m}$ were relevant to the single-species Sel 1 . The other selections required further subdivision to determine useful groupings of the target ensemble. This second stage of partitioning was based on the species composition of the trawl catches. For each integration interval, the species proportion by weight in the nearest trawl catch, taken at an appropriate depth, was assumed to be representative of the echo-traces. Where trawl catches were small, two or more hauls in the vicinity were combined to give more precise species proportions. If the catches were large enough to provide welldefined size histograms, the catch proportions of each species or species group were averaged. If the catches were very small, the fish quantities were summed and the total was treated as though it was one haul.

During the first four surveys, Sel 2 and Sel 3 were partitioned using the catch compositions of the frame trawl and the bottom trawl, respectively. During the fifth survey, only the pelagic trawl was used for echo-trace sampling. No allocations to Sel 3 were made in the absence of bottom trawl data. In the fifth survey, the echo-traces previously allocated to Sel 3 were now included in Sel 2, which was then parti- 
tioned according to the pelagic trawl catches. The change of sampling gear has introduced some uncertainty in the partitioning in the fifth survey compared to the earlier results. However, the pelagic trawl is clearly superior to the methods previously used for echo-trace sampling. This one gear is capable of sampling all the stock components, which previously required two gears. The main question to be considered for all the gears is the relative catching efficiency between large and small fish, in particular, between the Nile perch and the small pelagics i.e. dagaa and haplochromines. Conversion factors were determined from catch comparison experiments to ensure that the catch proportions registered by all the gears are comparable between the five surveys. The two-stage partitioning ended with the NASC being divided between the following five categories: (1) dagaa; (2) haplochromines; (3) Nile perch; (4) Caridina (C. nilotica) and (5) others.

The "others" category included all the additional species, which could not be individually determined, notably B. profundus, Synodontis spp. and the tilapia, O. niloticus. The acoustic and fishing data collected on our surveys did not allow any finer discrimination of the species composition than that indicated above.

\subsection{Data analysis}

To obtain total abundance estimates, we assumed the NASC of the unobserved near-surface water would be the same as that of the top layer. The observed NASC was increased accordingly.

The acoustic abundances were determined from the mean NASC multiplied by the water area of each square in a $15 \times 15 \mathrm{nmi}$ grid. To compare changes with latitude and water depth, the abundances were aggregated in the four zones illustrated in Fig. 4 The zonal boundaries were chosen on convenient political and bathymetry lines. The northern/southern divide was at the Tanzanian border (latitude $01^{\circ} \mathrm{S}$ ). The offshore/inshore zones corresponded to water depths more or less than $40 \mathrm{~m}$, respectively.

Target strength functions are required to convert the acoustic measurements to biomass. These have the form TS $=20 \log _{10}(L)-b_{20}$ where the factor $b_{20}$ depends on the species but not on the fish length $L$ (Foote, 1987). The TS functions relevant to Lake Victoria are not well known. We conducted limited experimental investigations on Nile perch, $L$. niloticus and dagaa, $R$. argentea in cages. The results suggest the following values for $b_{20}$, although their accuracy is uncertain: L. niloticus $66 \mathrm{~dB} ; R$. argentea $72 \mathrm{~dB}$.

In the absence of any other information, we have assumed the same TS function for all the small pelagics in the lake. In the case of $C$. nilotica, we have assumed a bulk TS of $-49 \mathrm{~dB}$ $\mathrm{kg}^{-1}$, taken from the results on similar crustaceans reported by Pieper (1979). In view of the uncertainty in these assumptions, it is emphasised that our biomass estimates must be considered as indices rather than absolute abundances.

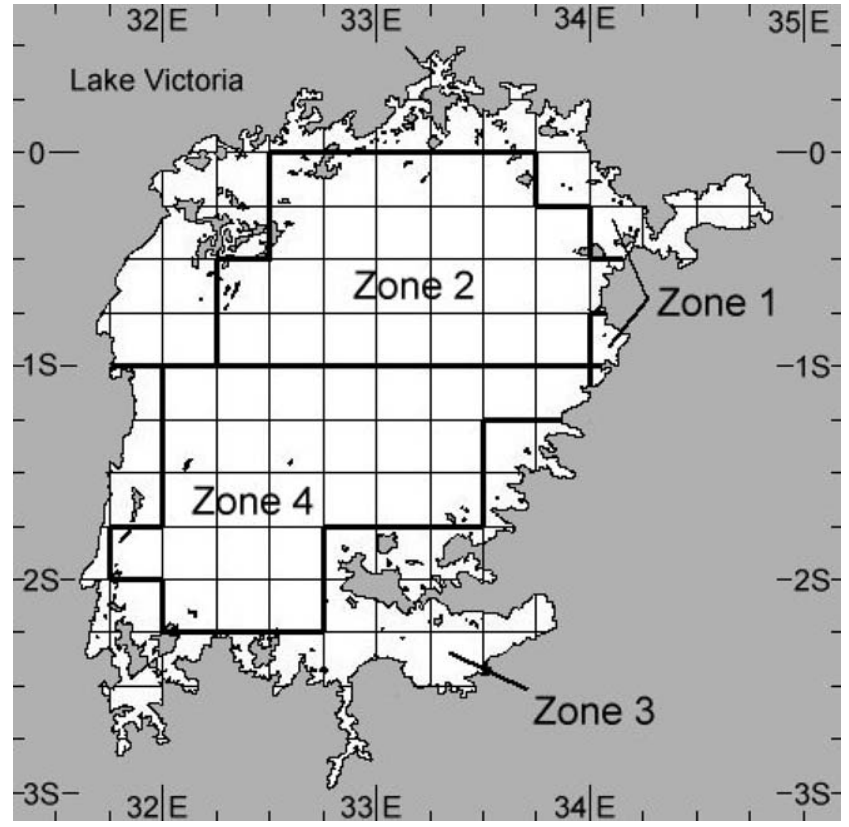

Fig. 4. Chart of the squares grid and the zones used in the analysis. The zones are (1) north inshore, (2) north offshore, (3) south inshore and (4) south offshore. The offshore/inshore divide is based on the mean water depth in the square being more or less than $40 \mathrm{~m}$.

\section{Results}

\subsection{Biomass trends}

Fig. 5 shows the total biomass and the partitioned indices for four of the species groups described above. The "small pelagic" group comprises all of the dagaa and Haplochromis species combined. The small pelagics were further divided in the analysis, however, the results were highly variable. A much clearer picture of the ecological trends emerges when the small pelagics are considered as one species group.

The mean total biomass index from all the surveys was $2.17 \times 10^{6}$ ton, corresponding to a Standing Crop (SC) of 31.0 ton $\mathrm{km}^{-2}$, of which L. niloticus constituted $59.3 \%, R$. argentea $22.4 \%$, haplochromines $15.0 \%$, C. nilotica $1.1 \%$ and other species 2.2\%. For comparison, Moreau (1995) found SC values around 27 ton $\mathrm{km}^{-2}$ in the early 1970s, before the Nile perch upsurge, rising to 43 ton $\mathrm{km}^{-2}$ in the mid 1980s.

The trends were investigated by linear regression of the aggregated biomass indices against time $(n=5$, Fig. 5 . Each index had a coefficient of variation (CV) around $25 \%$ due to sampling error. A strong seasonal dependence is evident. The average biomass index in August is $18.6 \pm 0.5 \%$ higher than that in February. The regression slope should, nevertheless, give a good indication of the trends over the 2 years. Any consistent seasonal effect could influence the regression intercept, but not the slope.

The total biomass index did not change much over the 2 years of the acoustic survey programme. At the species level, however, considerable changes were observed. Comparing the same seasons between years, our results show a 

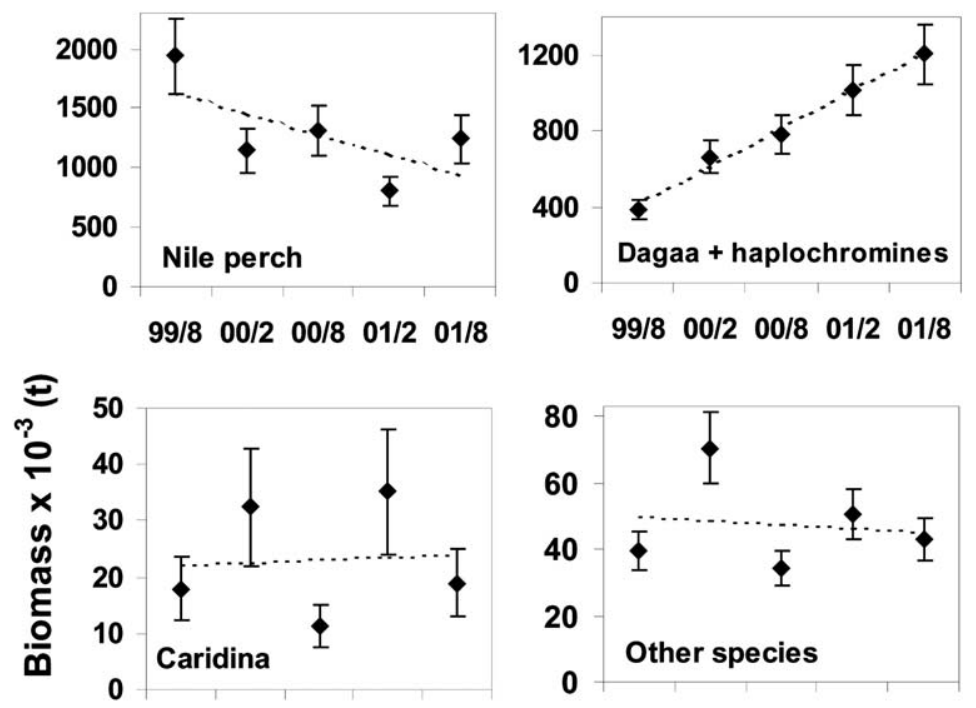

99/8 00/2 00/8 01/2 01/8

$99 / 8 \quad 00 / 2 \quad 00 / 8 \quad 01 / 2 \quad 01 / 8$

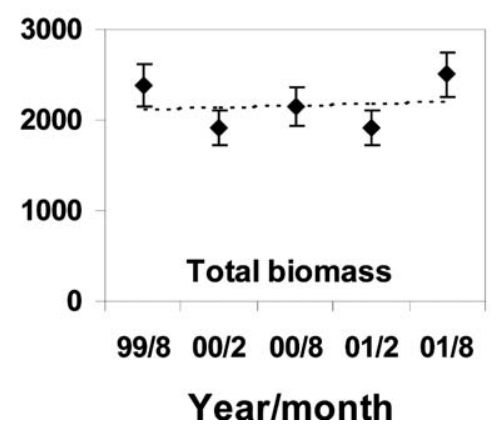

Fig. 5. Biomass indices from acoustic surveys of Lake Victoria 1999-2001. Points are the individual survey results. Bars show standard errors. Dashed lines: trends from linear regression of the five indices against time.

declining Nile perch stock (significance level 95\%), while the small pelagics increased substantially over the same 2 -year period. This is consistent with the observation of Witte et al. (2000) that the haplochromine population was increasing in the late 1990s.

\subsection{Bathyspatial distribution}

The acoustic surveys showed how fish were distributed through the water column and across the lake. Fig. 6 shows how the mean SC changed between the four zones.
In the shallow zones the all-species SC was around twice that in the offshore zones. Most of the variation comes from the Nile perch, which are primarily near the bottom. When the lake was stratified, there were few echoes below the oxycline.

In the case of the small pelagics, substantial quantities were observed in the upper waters throughout the lake. The dominant species in the pelagic zone were dagaa, $R$. argentea in surface layers and haplochromines, which were generally in deeper layers. The dagaa were less abundant inshore in August compared to February. The SC was much the same in
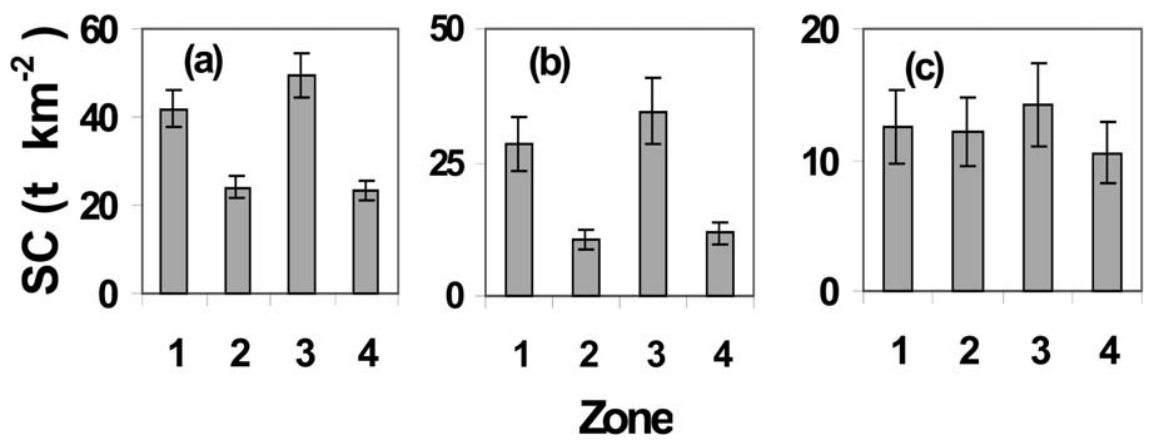

Fig. 6. Distribution of the Standing Crop (means for all five surveys) between the zones of Lake Victoria—1, 2 north; 3, 4 south; 1, 3 shallow; 2, 4 deep. Bars show standard errors. (a) Total biomass, (b) Nile perch, (c) small pelagics. 
Table 1

Dissolved oxygen concentrations \pm 1 standard error $\left(\mathrm{mg} \mathrm{l}^{-1}\right)$ near the lakebed by water depth and season. Mean results from measurements during surveys in 2000

\begin{tabular}{lll}
\hline & Season & \\
& February & August \\
\hline Inshore $(<40$ m depth $)$ & $4.3 \pm 0.8$ & $6.2 \pm 0.6$ \\
Offshore $(>40$ m depth) & $1.2 \pm 0.7$ & $6.3 \pm 0.3$ \\
\hline
\end{tabular}

all zones. The small pelagics were patchily distributed in open water, but more uniformly than the less abundant $C$. nilotica, $B$. profundus and Synodontis species.

The consistency of the spatial distribution was investigated through paired comparisons between surveys of the SC in each $15 \times 15 \mathrm{nmi}$ square. Backward stepwise regression was used to determine the Pearson moment correlation coefficient. The August distributions were positively and significantly correlated with one another, as were those of the February surveys $(P<0.01)$. The cross-correlations between the February and August surveys were much less consistent.

\subsection{Environmental factors}

During February, most of the deeper lake is stratified with richly oxygenated water lying above a nearly anoxic layer. In August the water is well mixed with a much higher concentration of dissolved oxygen. Table 1] shows the concentrations recorded during the two surveys in 2000. Note that $3 \mathrm{mg} \mathrm{l}^{-1}$ is the critical level of dissolved oxygen below which most fish species are not able to survive (Chapman et al., 1995; Wanink et al., 2001).

The inshore oxygen concentration remained high throughout the year. The seasonal changes were much stronger in the deeper water.

\section{Discussion}

This paper describes the first comprehensive acoustic assessment of fish stocks in Lake Victoria. Due to the pioneering nature of the work, some changes in methodology were adopted as techniques developed. The initial survey design was more stratified than that adopted later, the survey duration was extended to allow more fishing and a higher degree of area coverage, and a new gear was introduced to improve echo-trace sampling. These changes could bias the observed trends and the species proportions from echo-trace partitioning. The results are, nevertheless, our best estimates of the biomass indices and the distribution of fish stocks. The experience gained should allow future surveys to be conducted with a more consistent methodology. Consistency in acoustic surveying is important for reliable indication of trends in the biomass and its principal components.

The vertical echo-sounder cannot integrate fish in the near-surface layer. Corrections can be made if the nearsurface aggregations are similar to those observed further down, however, substantial coastal areas of Lake Victoria are less than $10 \mathrm{~m}$ deep. Estimates made by present techniques are unsatisfactory in these circumstances. Horizontal sonar might be used in future surveys as a novel way to improve the coverage of the lake.

Better knowledge of the fish TS is needed to determine the biomass as an absolute measure rather than an index. Our experiments showed that the caged-fish technique works well for the robust Nile perch, however, they were restricted to juvenile specimens. Further work on larger fish is required. In the case of $R$. argentea, the mortality rate in the experimental cage was too high to give good results. Improved techniques are needed to maintain the captive fish in good condition. Future TS experiments should include other species, notably the pelagic haplochromines and the tilapia $O$. niloticus. It would also be useful to determine the TS of the lake fly larvae, Chaoborus spp., since they can produce strong planktonic echoes at night.

In addition to oxygen, the chlorophyll- $a$ concentration, water temperature and salinity were measured during the surveys. Seasonal differences in all these parameters were observed which could further influence the fish distribution. For example, higher fish densities were observed in warmer water i.e. in the coastal shallows compared to the central areas of the lake. This suggests that the water temperature is also an important determinant of the spatial distribution and variability of the fish stocks.

Understanding the behavioural ecology of fish is essential to the interpretation of acoustic surveys. Fish aggregation behaviour can change with the time of day and environmental conditions. This affects the characteristics of the echotraces (Aglen, 1994; Misund, 1997). In Lake Victoria, the scattering layers containing fish have different features from time to time. Inshore, the main layer was usually near the bottom during morning hours and in midwater during the afternoon. In the evening, fish were scattered all over the water column. In the open deeper part of the lake, the layer was always in midwater.

When periods with different fish aggregation behaviour are being compared, different criteria are needed for partitioning the echo-integrals. We used simple rules to make the partitioning as objective as possible, however, the possible bias in the partitioned results is unknown. The reliance on trawl catches for the species and size proportions could introduce substantial error. The relative catch selectivity on species as different as Nile perch and dagaa is a particularly difficult question.

There was a significant $(P>0.95)$ decline of the L. niloticus stock over the 2 years of our investigations. Fishing pressure is a primary reason for the decline, however, environmental changes could also be important. Oxygen depletion can deny large areas of the bottom to fish. This is thought to have contributed the past decline of the haplochromine stocks (Hecky et al., 1994). Anoxia forces the demersal population to concentrate inshore where they are more vulnerable to predation by L. niloticus (Witte et al., 1992, Kudhongania and Cordone, 1974). 
Some spatial separation of the species may be maintained, depending on the precise environmental conditions, since the small haplochromines can tolerate low-oxygen water unsuitable for the large perch (Fish, 1956; van Oijen et al., 1981; Chapman et al., 1995).

The important point here is that environmental and biological studies need to be included in the stock assessment process. All the factors motivating change must be considered together, to determine the true risk to the long-term future of sustainable fisheries.

\section{Acknowledgements}

Phase II of the LVFRP was supported by the European Development Fund and the Governments of Kenya, Tanzania and Uganda. We acknowledge the advice and support provided by many colleagues from the regional fishery research institutes (FIRRI, KMFRI and TAFIRI), the FRS Marine Laboratory in Scotland and the Hull International Fisheries Institute in England.

\section{References}

Aglen, A., 1994. Sources of error in acoustic estimation of fish abundance. In: Ferno, A., Olsen, S. (Eds.), Marine Fish Behaviour in Capture and Abundance Estimation. Fishing News Books, Oxford, UK, pp. 107-133.

Chapman, L.J., Kaufman, L.S., Chapman, C.A., Mckenzie, F.E., 1995. Hypoxia tolerance in 12 species of East African cichlids-potential for low-oxygen refugia in Lake Victoria. Conserv. Biol., 1274-1288.

Fish, G.R., 1956. Some aspects of respiration of six species of fish from Uganda. J. Exp. Biol. 33, 186-195.

Foote, K.G., 1987. Fish target strengths for use in echo-integrator surveys. J. Acoust. Soc. Am. 82, 981-987.
Goudswaard, P.C., Witte, F., Katunzi, E.F.B., 2002. The tilapiine fish stocks of Lake Victoria before and after the Nile perch upsurge. J. Fish Biol. 60, 838-856.

Hecky, R.E., Bugenyi, F.W.B., Ochumba, P., Talling, J.F., Mugidde, R., Gophen, M., Kaufman, L., 1994. Deoxygenation of Lake Victoria, East Africa. Limnol. Oceanogr. 39, 1476-1481.

Kudhongania, A.W., Cordone, A.J., 1974. Bathospatial distribution patterns and biomass estimates of the major demersal fishes in Lake Victoria. Afr. J. Trop. Hydrobiol. Fish. 3, 15-31.

MacLennan, D.N., Simmonds, E.J., 1992. Fisheries Acoustics. Chapman and Hall, London p. 325.

Misund, O.A., 1997. Underwater acoustics in marine fisheries and fisheries research. Rev. Fish Biol. Fish. 7, 1-34.

Moreau, J., 1995. Analysis of species changes in Lake Victoria using ECOPATH, a multispecies trophic model. In: Pitcher, T.J., Hart, P.J. (Eds.), The Impact of Species Changes in African Lakes. Chapman and Hall, London, pp. 137-161.

van Oijen, M.J.P., Witte, F., Witte-Maas, E.L.M., 1981. An introduction to ecological and taxonomic investigations on the cichlids from the Mwanza Gulf of Lake Victoria. Neth. J. Zool. 31, 149-174.

Pieper, R.E., 1979. Euphausid distribution and biomass determined acoustically at $102 \mathrm{kHz}$. Deep Sea Res. 26, 687-702.

Reynolds, J.E., Greboval, D.F., 1988. Socio-economic effects of the evolution of Nile perch fisheries in Lake Victoria: a review. Com. Inland Fish. Afr. Tech. Pap., 17. Food and Agriculture Organisation of the United Nations, Rome, Italy.

Wanink, J.H., Kashindye, J.J., Goudswaard, P.C., Witte, F., 2001. Dwelling at the oxycline: does increased stratification provide a predation refugium for the Lake Victoria sardine Rastrineobola argentea? Freshwater Biol. 46, 75-85.

Witte, F., Goldschimidt, T., Wanink, J., van Oijen, M., Goudswaard, K., Witte-Maas, E., Bouton, N., 1992. The destruction of an endemic species flock: quantitative data on the decline of the haplochromine cichlids of Lake Victoria. Environ. Biol. Fishes 34, 1-28.

Witte, F., Msuku, B.S., Warink, J.H., Seehausen, O., Katunzi, E.F.B., Goudswaard, P.C., Goldschmit, T., 2000. Recovery of cichlid species in Lake Victoria: an examination of factors leading to differential extinction. Rev. Fish Biol. Fish. 10, 233-241. 